\title{
Design and Analysis High Gain PHEMT LNA for Wireless Application at $5.8 \mathrm{GHz}$
}

\author{
Kamil Pongot ${ }^{1,2}$, Abdul Rani Othman ${ }^{2}$, Zahriladha Zakaria ${ }^{2}$, Mohamad Kadim Suaidi ${ }^{2}$, \\ Abdul Hamid Hamidon' ${ }^{2}$ J.S. Hamidon ${ }^{2}$, Azman Ahmad ${ }^{1,2}$ \\ ${ }^{1}$ Bahagian Sumber Manusia, Majlis Amanah Rakyat (MARA) \\ Tingkat 17 \& 18 Ibu Pejabat MARA, Jalan Raja Laut, 50609 Kuala Lumpur, Malaysia \\ ${ }^{2}$ Centre of Telecommunication and Innovation (CETRI), Faculty of Electronics and Computer Engineering \\ Universiti Teknikal Malaysia Melaka (UTeM), Hang Tuah Jaya \\ 76100, Durian Tunggal, Melaka, Malaysia
}

\section{Article Info}

Article history:

Received Jan 20, 2015

Revised Apr 25, 2015

Accepted May 10, 2015

\section{Keyword:}

Cascaded and Cascoded LNA

IEEE 802.16

Inductive drain feedback

PHEMT LNA

\begin{abstract}
This research presents a design of a higher gain $(66.38 \mathrm{~dB})$ for PHEMT LNA using an inductive drain feedback technique for wireless application at 5.8GHz. The amplifier it is implemented using PHEMT FHX76LP transistor devices. The designed circuit is simulated with Ansoft Designer SV. The LNA was designed using T-network as a matching technique was used at the input and output terminal, inductive generation to the source and an inductive drain feedback. The low noise amplifier (LNA) using lumped-component provides a noise figure $0.64 \mathrm{~dB}$ and a gain $\left(\mathrm{S}_{21}\right)$ of $68.94 \mathrm{~dB}$. The output reflection $\left(\mathrm{S}_{22}\right)$, input reflection $\left(\mathrm{S}_{11}\right)$ and return loss $\left(\mathrm{S}_{12}\right)$ are $-17.37 \mathrm{~dB}$, $15.77 \mathrm{~dB}$ and $-88.39 \mathrm{~dB}$ respectively. The measurement shows the stability was at 4.54 and $3-\mathrm{dB}$ bandwidth of $1.72 \mathrm{GHz}$. While, the low noise amplifier (LNA) using Murata manufactured component provides a noise figure 0.60 $\mathrm{dB}$ and a gain $\left(\mathrm{S}_{21}\right)$ of $66.38 \mathrm{~dB}$. The output reflection $\left(\mathrm{S}_{22}\right)$, input reflection $\left(\mathrm{S}_{11}\right)$ and return loss $\left(\mathrm{S}_{12}\right)$ are $-13.88 \mathrm{~dB},-12.41 \mathrm{~dB}$ and $-89.90 \mathrm{~dB}$ respectively. The measurement shows the stability was at 6.81 and $3-\mathrm{dB}$ bandwidth of $1.70 \mathrm{GHz}$. The input sensitivity more than $-80 \mathrm{dBm}$ exceeded the standards required by IEEE 802.16.
\end{abstract}

Copyright () 2015 Institute of Advanced Engineering and Science. All rights reserved.

\section{Corresponding Author:}

Kamil Pongot

Bahagian Sumber Manusia, Majlis Amanah Rakyat (MARA)

Tingkat 17 \& 18 Ibu Pejabat MARA, Jalan Raja Laut, 50609 Kuala Lumpur, Malaysia.

Email: kamilpongot@yahoo.com.sg

\section{INTRODUCTION}

At this point, most of the developing and advanced country used $3 \mathrm{G}$ technologies due to the speedy delivery of information to users at a higher bit rate. However, the bit rate of $3 \mathrm{G}$ technology reserve at this point is still not enough due to the high demand from consumers, especially in wireless broadband. To overcome this problem, the use of WiMAX technology was introduced to consumers to enable effective connectivity at high bit rate to a new generation of consumer devices for adaptation latest applications that are available in the market [1].

Groups of telecommunication protocol using WiMAX technology are new trademark and standards in the provision of mobile and fixed internet access. Residential construction and opening of a planned township enterprise in free zones require high data transfer rate $(70 \mathrm{Mbps})$ and reach $(50 \mathrm{~km})$ to meet the needs of high bandwidth voice and data to support the growth of the industry [2]. WiMAX is a replacement technology for cellular phone technologies such as UMTS and GSM and can be used to increase capacity of the customer [3]. Therefore, the RF front-end receiver should be designed according to the latest specifications to support new trademark as set by the telecommunications protocols and allows it to operate in a multiple of applications on a single device. 
Design of LNA amplifiers for RF receiver front-end is to obey and comply with the new standards IEEE 802.16. It to ensure that the received signal can be processed to obtain information that is transmitted without interference noise. This can only be done when the designers are able to design an RF front-end receiver with the best characteristic in the entire system such as the higher gain, low noise figure and sufficient bandwidth to accommodate the needs of the latest applications available in the market for users using WiMAX technology.

To ensure high performance signal reception to meet the standards set by IEEE 802.16, a new design in architecture receiver RF front-end should be introduced to improve the performance of existing systems. A previous researcher reported covering the extension of communication distance for the system up to $50 \mathrm{~km}$ requires an overall gain from the range up to $50 \mathrm{~dB}$ [4], but to get a better performance for RF front-end receiver, we proposed for overall gain that introduce enhanced up to $65 \mathrm{~dB}$.

For WiMAX standard, the system is designed to accommodate up to 200 channel subscribers while the bandwidth of the system designed is between 1600 to $1700 \mathrm{MHz}$, which is triple than the standard 20 $\mathrm{MHz}$ for 200 sub-carriers. In addition, the noise figure proposed by the IEEE 802.16 (WiMAX) for the RF receiver front-end architecture must be less than $3 \mathrm{~dB}$. The input sensitivity of the system should cover the minimum sensitivity of $-80 \mathrm{dBm}[4]$.

In this paper, a new topology front end architecture using inductive drain feedback is used to achieve a gain more than $65 \mathrm{~dB}$, noise figure less than $3 \mathrm{~dB}$ and should provide bandwidth more than $1 \mathrm{GHz}$ is proposed in WiMAX application. Figure 1 shows the architecture configurable for direct conversion RF front-end receiver WiMAX at $5.8 \mathrm{GHz}$ is introduced. The development of combination LNA at the front-end of the receiver will be focused.

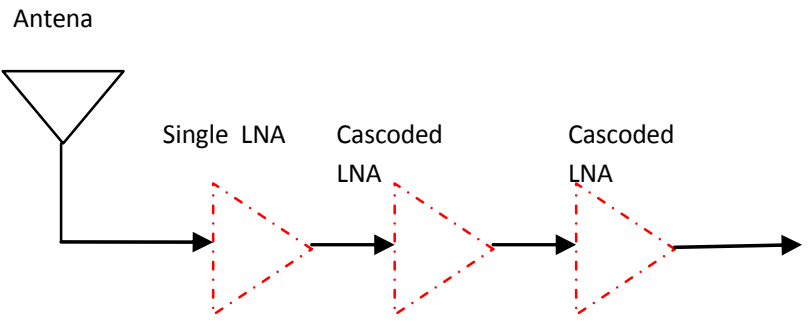

Figure 1. The new architecture for direct conversion RF front-end receiver WiMAX at $5.8 \mathrm{GHz}$

This configuration consisting of double stages cascoded LNA using inductive drain feedback combined with source inductive degeneration, inductive RF choke placed between the two LNA amplifier and the $\mathrm{T}$ matching network at the input and output ports. Were used inductive drain feedback at the cascoded topology has improved the gain of the LNA and will suit at matching output that it also helps in increasing the bandwidth. While the addition of an inductive source generation at cascoded LNA topology enhanced bandwidth, stability and improve input-output matching capabilities. The use of T-matching on a double stage cascoded LNA also has helped reduce the reverse isolation and noise figure.

\section{LNA THEORY}

Low noise amplifier (LNA) is a key factor in the improved performance of the RF front-end receiver. LNA in the WiMAX receiver application requires sufficient sensitivity to enable the receiver distinguish signal from the surrounding noise and interference to ensure that it can take an information signal sent by the transmitter. The gain, bandwidth, noise figure and linearity are the characteristic that can be controlled by the RF front-end designer that affect directly to the receiver sensitivity. Even so to control such features requires a deep understanding of the device amplifiers, active and passive components, and fabrication details to ensure the LNA amplifiers built to achieve optimal performance and only a slight tradeoff between the characteristic [5].

However, in this research, we only focused on variables such as gain, noise figure, stability, bandwidth, topology, and input and output matching for best performance of LNA amplifiers. The targeted Sparameter specification for the single LNA cascaded with double stages cascoded LNA amplifier is shown in Table 1.

IJECE Vol. 5, No. 3, June 2015 : $611-620$ 
Table 1. Targeted S-Parameters for a a single LNA cascaded with double stages cascoded LNA amplifier

\begin{tabular}{cc}
\hline S- parameter & $\begin{array}{c}\text { Single LNA cascaded with double } \\
\text { stages cascoded LNA }\end{array}$ \\
\hline Input reflection S11 $(\mathrm{dB})$ & $<-10 \mathrm{~dB}$ \\
Return Loss S12 (dB) & $<-10 \mathrm{~dB}$ \\
Forward Transfer S21 (dB) & $>+65 \mathrm{~dB}$ \\
Output Reflection loss S22 (dB) & $<-10 \mathrm{~dB}$ \\
Noise Figure (dB) & $<3 \mathrm{~dB}$ \\
Stability $(\mathrm{K})$ & $\mathrm{K}>1$ \\
Bandwidth $(\mathrm{MHz})$ & $>1000$ \\
\hline
\end{tabular}

\subsection{Stability, Noise Figure and Power Gain}

Stability is one of the important characteristics in designing LNA amplifiers. Determination of stability is essential to avoid oscillation occurs at the operating frequency. The oscillation is possible if either input or output port impedance has produced a negative real part. This would imply that $\Gamma_{\text {in }}>1$ or $\Gamma_{\text {out }}>1$. This because $\Gamma_{\text {in }}$ and $\Gamma$ out depend on the source and the load matching network. However, the stability of the amplifier depends on $\Gamma_{\mathrm{s}}$ and $\Gamma_{\mathrm{L}}$ as presented as matching network. If low noise amplifiers is not stable, it would become useless since major properties including bandwidth, gain, noise, linearity, DC power consumption and impedance matching can be significantly degraded. In this design, a good stability was achieved (unconditionally stable) by employing the signal flow theory and S-parameter [6]. Alternatively, the amplifier will be unconditionally stable, when the stability factor $(\mathrm{K})$ and delta factor $(\Delta)$ following necessary and sufficient conditions are met:

$$
K=\frac{1-\left|S_{11}\right|^{2}-\left|S_{22}\right|^{2}+|\Delta|^{2}}{2\left|S_{12} S_{21}\right|}>1
$$

and

$$
|\Delta|=\left|S_{11} S_{22}-S_{12} S_{21}\right|<1
$$

$(\mathrm{K}>1)$ and $(|\Delta|<1)$ is condition requirement for unconditional stability.

By using stability circle that is based on radius and center, the Table 2 below shows that the two circles need to draw both input and output.

\begin{tabular}{|c|c|c|}
\hline Input stability circle & & Output stability circle \\
\hline$\left|\Gamma_{I N \mid}\right|=S_{11}+\frac{S_{12} S_{21} \Gamma_{L}}{1-S_{22} \Gamma_{L}}=1$ & & $\left|\Gamma_{\text {oUT }}\right|=\left|S_{22}+\frac{S_{12} S_{21} \Gamma_{S}}{1-S_{11} \Gamma_{S}}\right|=1$ \\
\hline$\gamma_{i n}=\left|\frac{s_{12} s_{21}}{\left|s_{11}\right|^{2}-|\Delta|^{2}}\right|$ & Radius & $\gamma_{\text {out }}=\left|\frac{\mathrm{S}_{12} \mathrm{~S}_{21}}{\left|\mathrm{~S}_{22}\right|^{2}-|\Delta|^{2}}\right|$ Radius \\
\hline$C_{i n}=\frac{\left.S_{11}-\mid S^{*}{ }^{2}\right)^{*}}{\left|\mathbf{S}_{11}\right|^{2}-|\Delta|^{2}}$ & Center & $C_{i n}=\frac{\left(S_{22}-\Delta S^{*}{ }_{11}\right)^{*}}{\left|S_{22}\right|^{2}-|\Delta|^{2}}$ Center \\
\hline
\end{tabular}

Table 2. Input and output stability circle

These two circles are drawn on a Smith Chart using S-Parameter values of the FET, input matching $\Gamma_{\text {in }}$ output matching $\Gamma_{\text {out }}$. Figure 2 and Figure 3 shows the input and output stability circles. 


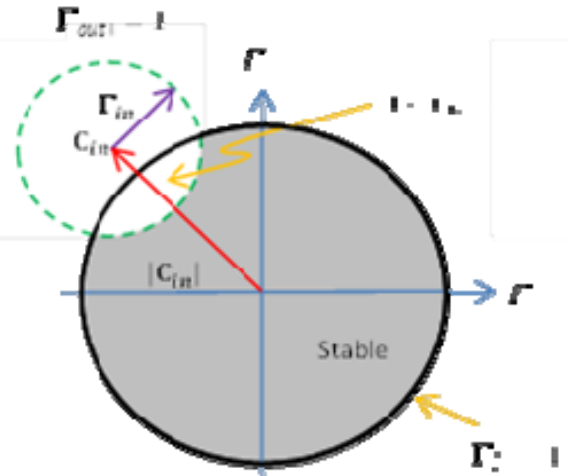

(a) $\left|S_{22}\right|<1$

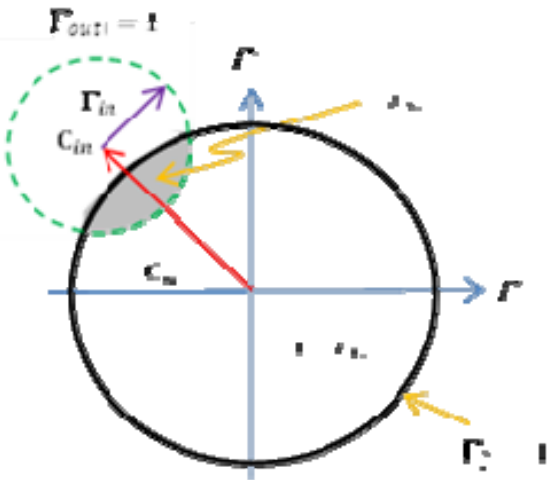

(b) $\left|S_{22}\right|>1$

Figure 2. Output Stability Circles [7]

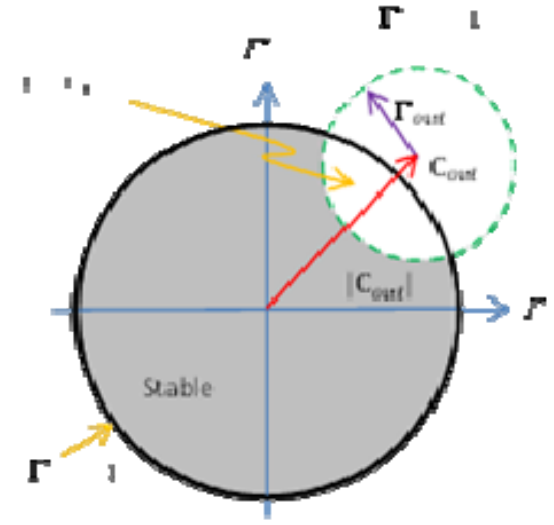

(a) $\left|S_{11}\right|<1$

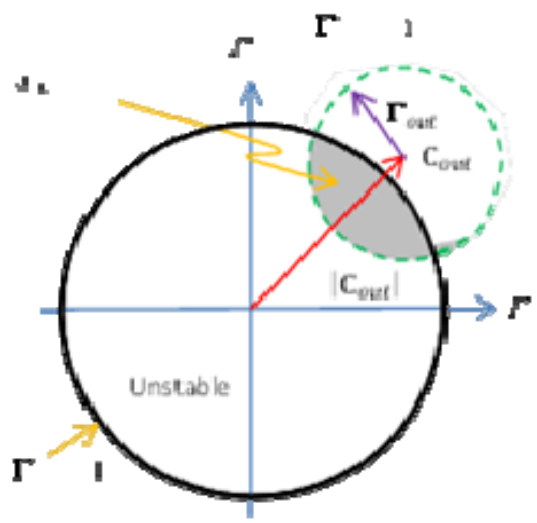

(b) $\left|S_{11}\right|>1$

Figure 3. Input Stability Circles [7]

Noise optimization is the most critical step procedure in the LNA design. The best way to make the balance optimization of noise figure and gain using constant gain circles and circles of constant noise figure. 2-port transistor has a minimum value of the noise figure at the specified admittance given by the equation (3), [8]:

$$
F=F_{\min }+\frac{R_{N}}{G_{S}}\left|Y_{s}-Y_{o p t}\right|^{2}
$$

For low noise transistors, manufacturers usually provide $F_{\min }, R_{N}$ and $Y_{\text {opt }}$ by frequencies. $N$ defined by the formula for desired noise figure, shown in equation (4):

$$
N=\frac{\left|\Gamma_{s}-\Gamma_{\text {opt }}\right|^{2}}{1-\left|\Gamma_{S}\right|^{2}}=\frac{F-F_{\min }}{4 R_{N} / Z_{0}}\left|1+\Gamma_{o p t}\right|^{2}
$$


The Power gain of 2-port networks with circuit impedance or load impedance of the power amplifier are represented with scattering coefficient classified into Available Power Gain, Power Transducer Gain and Operating Power Gain [9].

Operating power gain $\left(\mathrm{G}_{\mathrm{P}}\right)$, is the ratio between the power delivered to the load $\left(\mathrm{P}_{\mathrm{L}}\right)$ and the power input $\left(\mathrm{P}_{\text {in }}\right)$ to the network. The Operating Power Gain can be specified as an equation (5), [8]:

$$
G_{P}==\frac{P_{L}}{P_{\text {in }}}=\frac{\left|S_{21}\right|^{2}\left(1-\left|\Gamma_{L}\right|^{2}\right)}{\left(1-\left|\Gamma_{\text {in }}\right|^{2}\right) 1-\left.S_{22} \Gamma_{L}\right|^{2}}
$$

Available power gain $\left(\mathrm{G}_{\mathrm{A}}\right)$ is the ratio between the power available from the network $\left(\mathrm{P}_{\mathrm{avn}}\right)$ and the power available from the source $\left(\mathrm{P}_{\mathrm{avs}}\right)$ as shown in equation (6), [8]:

$$
G_{A}=\frac{P_{a v n}}{P_{a v s}}=\frac{1-\left|\Gamma_{S}\right|^{2}}{\left|1-S_{11} \Gamma_{S}\right|^{2}}\left|S_{21}\right|^{2} \frac{1}{\left|1-S_{22} \Gamma_{L}\right|^{2}}
$$

Transducer power gain $\left(\mathrm{G}_{T}\right)$ is the ratio between the power delivered to the load $\left(\mathrm{P}_{\mathrm{L}}\right)$ and the power available from the source $\left(\mathrm{P}_{\text {in }}\right)$ as shown in equation $(7),[8]$ :

$$
G_{T}=\frac{P_{L}}{P_{i n}}=\frac{\left|S_{21}\right|^{2}\left(1-\left|\Gamma_{S}\right|^{2}\right)\left(1-\left|\Gamma_{L}\right|^{2}\right)}{\left|\left(1-S_{11} \Gamma_{S}\right)\left(1-S_{22} \Gamma_{L}\right)-\left(S_{12} S_{21} \Gamma_{S} \Gamma_{L}\right)\right|^{2}}
$$

\section{DESIGN OF LNA CASCADED WITH DOUBLE STAGES CASCODED LNA}

In this research, the three-stage LNA can be designed by cascading by using single LNA cascaded with double stage cascoded LNA as shown on Figure 4.

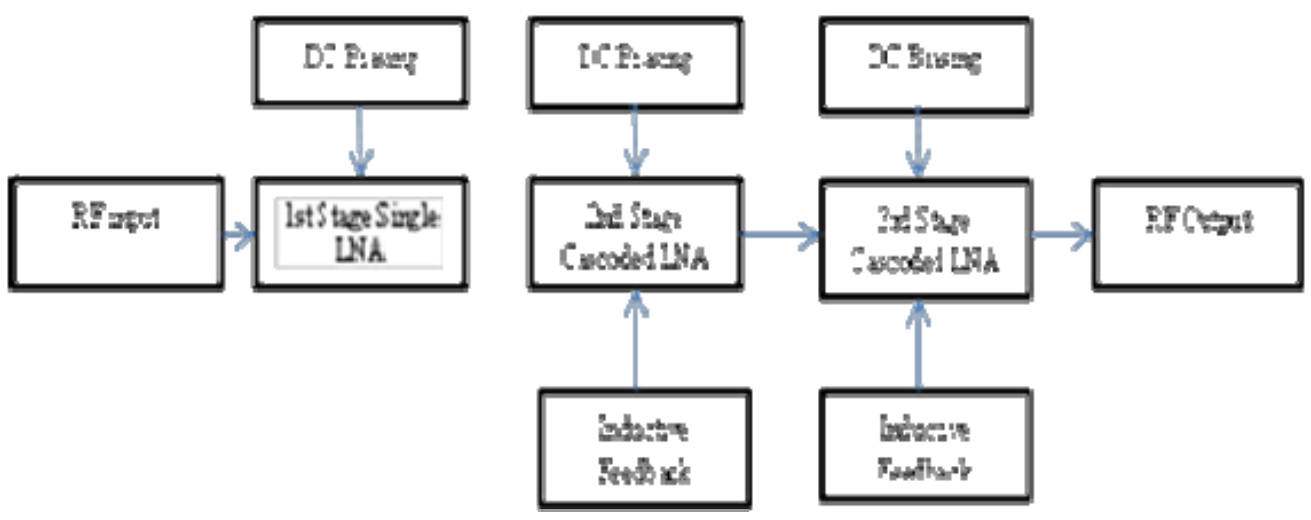

Figure 4. Three Stages LNA Block Diagram

There can be several ways to attain at the design; three different active devices (transistors) can be utilized if the same device is not able to handle the signal level in progressive stages. As the LNA under consideration is a small signal amplifier, all the three stages use the same transistor device. The inter-stage matching network is needed because this conception is wideband amplifier, and the input and output

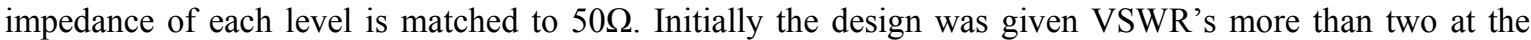
input and output ports, merely by using the ADS optimization tools VSWR's are reduced to less than two to minimize the reflections at the input and output ports.

Figure 5 shows the complete schematic single LNA cascaded with double stage cascoded LNA using inductive feedback. The selection of the transistor is important in the design of LNA. The design of the single LNA with double stages cascoded LNA is based on the specification in Table 1. For reasonable gain and low noise figure at the required frequency requirement, the transistor used for the design of LNA is PHEMT Transistor FHX76LP. The transistor parameter at frequency $5.8 \mathrm{GHz}$ are $\mathrm{S}_{11}=0.712\left\llcorner-86.54, \mathrm{~S}_{12}=\right.$ 
$0.065\left\llcorner 33.88, \mathrm{~S}_{21}=8.994\left\llcorner 178.66\right.\right.$ and $\mathrm{S}_{22}=0.237\left\llcorner-10.46\right.$, where the parameters were obtained at $\mathrm{V}_{\mathrm{DD}}=$ $2 \mathrm{~V}$ and $\mathrm{I}_{\mathrm{DS}}=10 \mathrm{~mA}$ of bias set at PHEMT.

From the S-parameters, determining the overall performance of LNA can be determined by calculating the transducer gain (GT), noise figure (NF) and the input and output standing wave ratios,

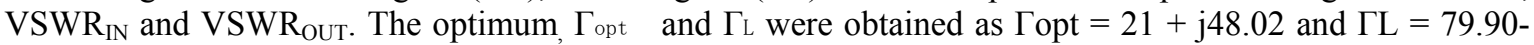
j7.299 for cascoded LNA. While, $\Gamma$ opt $=18.41+\mathrm{j} 50.12$ and $\Gamma \mathrm{L}=79.913-\mathrm{j} 7.304$ for a single LNA.

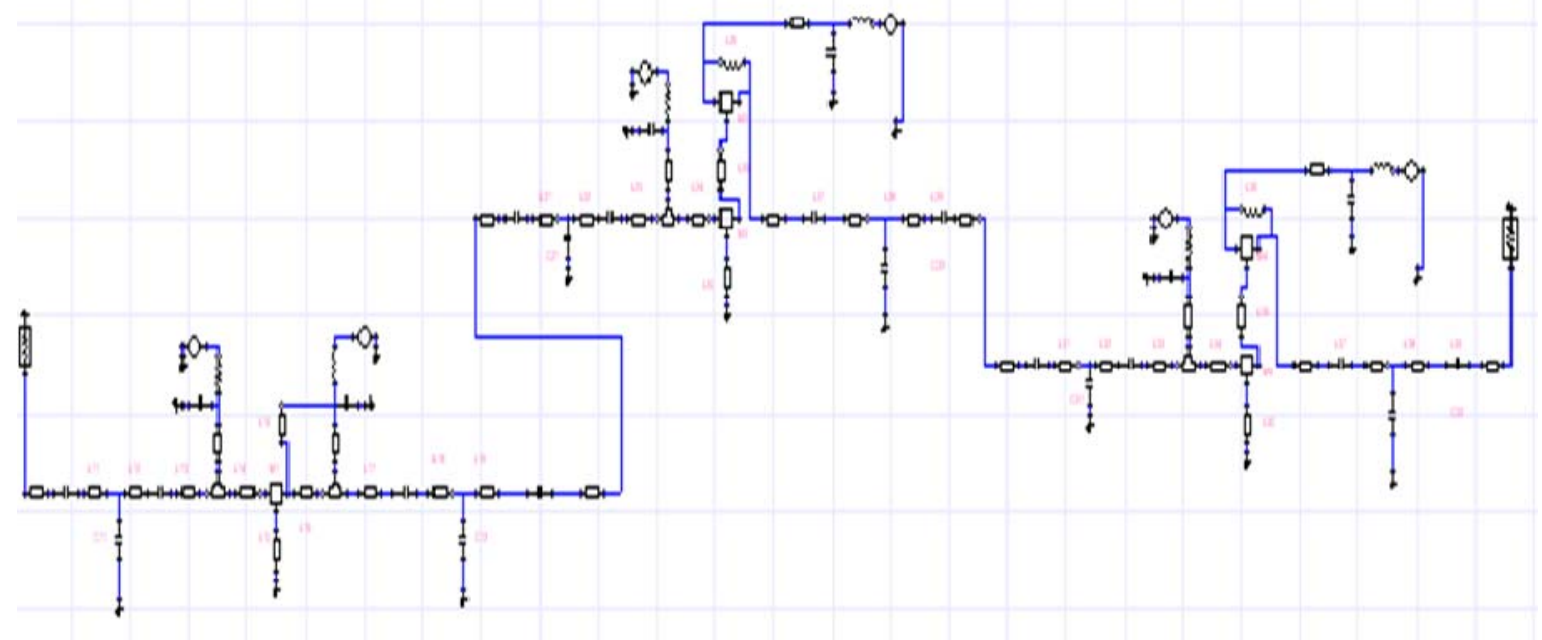

Figure 5. The complete schematic LNA cascaded with double stage cascoded LNA using inductive feedback

In this configuration, it combines LNA at the first stage, then use cascoded LNA with inductive feedback at the drain on the second and third stage. The proposed LNA design is based on a source degenerated topology $\left(\mathrm{L}_{10}\right)$, inductive shunt peaking at the drain $\left(\mathrm{L}_{15}\right)$ and T-matching network at the input and output impedance (input impedance matching at $\mathrm{L}_{11}, \mathrm{~L}_{12}, \mathrm{C}_{11}$, and output impedance matching at $\mathrm{L}_{18}, \mathrm{~L}_{19}$, $\mathrm{C}_{12}$ ). While the double stages cascoded LNA topology using latest techniques consisting of inductive feedback $\left(\mathrm{L}_{26}\right.$ and $\left.\mathrm{L}_{36}\right)$ are at drain $\mathrm{M}_{2}$ and $\mathrm{M}_{4}$, inductive generation source $\left(\mathrm{L}_{20}\right.$ and $\left.\mathrm{L}_{30}\right)$ connected to the source of the $\mathrm{M}_{3}$ and $\mathrm{M}_{5}$. In Addition, there $\mathrm{L}_{25}$ and $\mathrm{L}_{35}$ inductive RF choke were placed between the source drain on the $\mathrm{M}_{2}$ and $\mathrm{M}_{3}$, and the source drain on the $\mathrm{M}_{4}$ and $\mathrm{M}_{5}$ respectively. This topology also used the Tmatching network at the input and output impedance (input impedance matching component at $\mathrm{L}_{21}, \mathrm{~L}_{22}, \mathrm{~L}_{31}$, $\mathrm{L}_{32}, \mathrm{C}_{21}$ and $\mathrm{C}_{31}$ and output impedance matching component at $\mathrm{L}_{28}, \mathrm{~L}_{29}, \mathrm{~L}_{38}, \mathrm{~L}_{39}, \mathrm{C}_{22}$ and $\mathrm{C}_{32}$ ). By using Ansoft Designer SV, Smith Chart matching technique, the lumped-components for the amplifier are shown in Table 3. While the LNA amplifier for Murata-component shown in Table 4.

Table 3. LNA Amplifier parameters with Lumped-Component

\begin{tabular}{|c|c|c|c|c|c|c|c|c|c|c|c|c|}
\hline & \multicolumn{12}{|c|}{ Lumped-Components } \\
\hline $\begin{array}{l}1^{\text {st }} \text { Stage } \\
\text { LNA }\end{array}$ & $\mathrm{L}_{10}(\mathrm{nH})$ & $\mathrm{L}_{11}(\mathrm{nH})$ & $\mathrm{L}_{12}(\mathrm{nH})$ & $\mathrm{L}_{13}(\mathrm{nH})$ & $\mathrm{L}_{14}(\mathrm{nH})$ & $\mathrm{L}_{15}(\mathrm{nH})$ & $\mathrm{L}_{16}(\mathrm{nH})$ & $\mathrm{L}_{17}(\mathrm{nH})$ & $\mathrm{L}_{18}(\mathrm{nH})$ & $\mathrm{L}_{19}(\mathrm{nH})$ & $\mathrm{C}_{11}(\mathrm{pF})$ & $\mathrm{C}_{12}(\mathrm{pF})$ \\
\hline $\begin{array}{l}\text { Value } \\
2^{\text {nd }} \text { Stage } \\
\text { Cascoded } \\
\text { LNA }\end{array}$ & $\begin{array}{c}0.078 \\
\mathrm{~L}_{20}(\mathrm{nH})\end{array}$ & $\begin{array}{c}1.346 \\
\mathrm{~L}_{21}(\mathrm{nH})\end{array}$ & $\begin{array}{c}1.371 \\
\mathrm{~L}_{22}(\mathrm{nH})\end{array}$ & $\begin{array}{c}0.449 \\
\mathrm{~L}_{23}(\mathrm{nH})\end{array}$ & $\begin{array}{c}0.439 \\
\mathrm{~L}_{24}(\mathrm{nH})\end{array}$ & $\begin{array}{c}1.271 \\
\mathrm{~L}_{25}(\mathrm{nH})\end{array}$ & $\begin{array}{c}0.445 \\
\mathrm{~L}_{26}(\mathrm{nH})\end{array}$ & $\begin{array}{c}1.366 \\
\mathrm{~L}_{27}(\mathrm{nH})\end{array}$ & $\begin{array}{c}1.195 \\
\mathrm{~L}_{28}(\mathrm{nH})\end{array}$ & $\begin{array}{c}1.368 \\
\mathrm{~L}_{29}(\mathrm{nH})\end{array}$ & $\begin{array}{c}0.264 \\
\mathrm{C}_{21}(\mathrm{pF})\end{array}$ & $\begin{array}{c}0.010 \\
\mathrm{C}_{22}(\mathrm{pF})\end{array}$ \\
\hline $\begin{array}{l}\text { Value } \\
3^{\text {rd }} \text { Cascoded } \\
\text { LNA }\end{array}$ & $\begin{array}{c}0.064 \\
\mathrm{~L}_{30}(\mathrm{nH})\end{array}$ & $\begin{array}{c}1.346 \\
\mathrm{~L}_{31}(\mathrm{nH})\end{array}$ & $\begin{array}{c}1.016 \\
\mathrm{~L}_{32}(\mathrm{nH})\end{array}$ & $\begin{array}{c}0.698 \\
\mathrm{~L}_{33}(\mathrm{nH})\end{array}$ & $\begin{array}{c}0.367 \\
\mathrm{~L}_{34}(\mathrm{nH})\end{array}$ & $\begin{array}{c}1.159 \\
\mathrm{~L}_{35}(\mathrm{nH})\end{array}$ & $\begin{array}{c}9.000 \\
\mathrm{~L}_{36}(\mathrm{nH})\end{array}$ & $\begin{array}{c}1.367 \\
\mathrm{~L}_{37}(\mathrm{nH})\end{array}$ & $\begin{array}{c}0.658 \\
\mathrm{~L}_{38}(\mathrm{nH})\end{array}$ & $\begin{array}{c}1.369 \\
\mathrm{~L}_{39}(\mathrm{nH})\end{array}$ & $\begin{array}{c}0.100 \\
\mathrm{C}_{31}(\mathrm{pF})\end{array}$ & $\begin{array}{c}0.600 \\
\mathrm{C}_{32}(\mathrm{pF})\end{array}$ \\
\hline Value & 0.084 & 1.318 & 1.278 & 0.658 & 0.283 & 1.139 & 9.560 & 1.368 & 0.658 & 0.228 & 0.500 & 0.750 \\
\hline
\end{tabular}


Table 4. LNA Amplifier parameters with Murata-Component

\begin{tabular}{|c|c|c|c|c|c|c|c|c|c|c|c|c|}
\hline & \multicolumn{12}{|c|}{ Murata-Components } \\
\hline $\begin{array}{ll}1^{\text {st }} & \text { Stage } \\
\text { LNA } & \end{array}$ & $\mathrm{L}_{10}(\mathrm{nH})$ & $\mathrm{L}_{11}(\mathrm{nH})$ & $\mathrm{L}_{12}(\mathrm{nH})$ & $\mathrm{L}_{13}(\mathrm{nH})$ & $\mathrm{L}_{14}(\mathrm{nH})$ & $\mathrm{L}_{15}(\mathrm{nH})$ & $\mathrm{L}_{16}(\mathrm{nH})$ & $\mathrm{L}_{17}(\mathrm{nH})$ & $\mathrm{L}_{18}(\mathrm{nH})$ & $\mathrm{L}_{19}(\mathrm{nH})$ & $\mathrm{C}_{11}(\mathrm{pF})$ & $\mathrm{C}_{12}(\mathrm{pF})$ \\
\hline $\begin{array}{l}\text { Value } \\
2^{\text {nd }} \quad \text { Stage } \\
\text { Cascoded } \\
\text { LNA }\end{array}$ & $\begin{array}{c}0.078 \\
\mathrm{~L}_{20}(\mathrm{nH})\end{array}$ & $\begin{array}{c}1.346 \\
\mathrm{~L}_{21}(\mathrm{nH})\end{array}$ & $\begin{array}{c}1.372 \\
\mathrm{~L}_{22}(\mathrm{nH})\end{array}$ & $\begin{array}{c}0.449 \\
\mathrm{~L}_{23}(\mathrm{nH})\end{array}$ & $\begin{array}{c}0.440 \\
\mathrm{~L}_{24}(\mathrm{nH})\end{array}$ & $\begin{array}{c}1.270 \\
\mathrm{~L}_{25}(\mathrm{nH})\end{array}$ & $\begin{array}{c}0.445 \\
\mathrm{~L}_{26}(\mathrm{nH})\end{array}$ & $\begin{array}{c}1.366 \\
\mathrm{~L}_{27}(\mathrm{nH})\end{array}$ & $\begin{array}{c}1.196 \\
\mathrm{~L}_{28}(\mathrm{nH})\end{array}$ & $\begin{array}{c}1.368 \\
\mathrm{~L}_{29}(\mathrm{nH})\end{array}$ & $\begin{array}{c}0.1 \\
\mathrm{C}_{21}(\mathrm{pF})\end{array}$ & $\begin{array}{c}0.3 \\
\mathrm{C}_{22}(\mathrm{pF})\end{array}$ \\
\hline $\begin{array}{l}\text { Value } \\
3^{\text {rd }} \text { Cascoded } \\
\text { LNA }\end{array}$ & $\begin{array}{l}0.077 \\
\mathrm{~L}_{30}(\mathrm{nH})\end{array}$ & $\begin{array}{l}1.345 \\
\mathrm{~L}_{31}(\mathrm{nH})\end{array}$ & $\begin{array}{l}1.016 \\
\mathrm{~L}_{32}(\mathrm{nH})\end{array}$ & $\begin{array}{l}0.676 \\
\mathrm{~L}_{33}(\mathrm{nH})\end{array}$ & $\begin{array}{l}0.3669 \\
\mathrm{~L}_{34}(\mathrm{nH})\end{array}$ & $\begin{array}{l}1.159 \\
\mathrm{~L}_{35}(\mathrm{nH})\end{array}$ & $\begin{array}{c}1.365 \\
\mathrm{~L}_{36}(\mathrm{nH})\end{array}$ & $\begin{array}{l}0.053 \\
\mathrm{~L}_{37}(\mathrm{nH})\end{array}$ & $\begin{array}{l}1.112 \\
\mathrm{~L}_{38}(\mathrm{nH})\end{array}$ & $\begin{array}{l}1.369 \\
\mathrm{~L}_{39}(\mathrm{nH})\end{array}$ & $\begin{array}{c}0.3 \\
\mathrm{C}_{31}(\mathrm{pF})\end{array}$ & $\begin{array}{c}0.5 \\
\mathrm{C}_{32}(\mathrm{pF})\end{array}$ \\
\hline Value & 0.081 & 0.227 & 0.705 & 0.657 & 0.365 & 1.138 & 1.372 & 0.658 & 0.225 & 0.220 & 0.3 & 0.7 \\
\hline
\end{tabular}

\section{RESULTS}

Based on Figure 6 shows the s-parameters output of the lumped-component in used in the topology design. The Gain at $5.8 \mathrm{GHz}$ arising from consumption of lumped-component in this topology was $68.94 \mathrm{~dB}$. The gain is found to be nearly same as was calculated during the design procedure. In addition, the use of lumped - components of this topology has produced a 3-dB bandwidth of $1.72 \mathrm{GHz}$. The measured return loss $\mathrm{S}_{12}$ is $-88.39 \mathrm{~dB}$ while the output reflection loss $\mathrm{S}_{22}$ is $-17.37 \mathrm{~dB}$, and input reflection $\mathrm{S}_{11}$ is $-15.77 \mathrm{~dB}$. While Figure 7 shown, the stability factor obtained after matching load is 4.54 at $5.8 \mathrm{GHz}$ frequency. The value of stability obtained is greater than 1 , and the LNA amplifiers are currently in a state of unconditionally stable. Figure 8 shown noise figure of $0.64 \mathrm{~dB}$ over the band is achieved. Thus, these values achieved the design specification, as stated in Table 2.

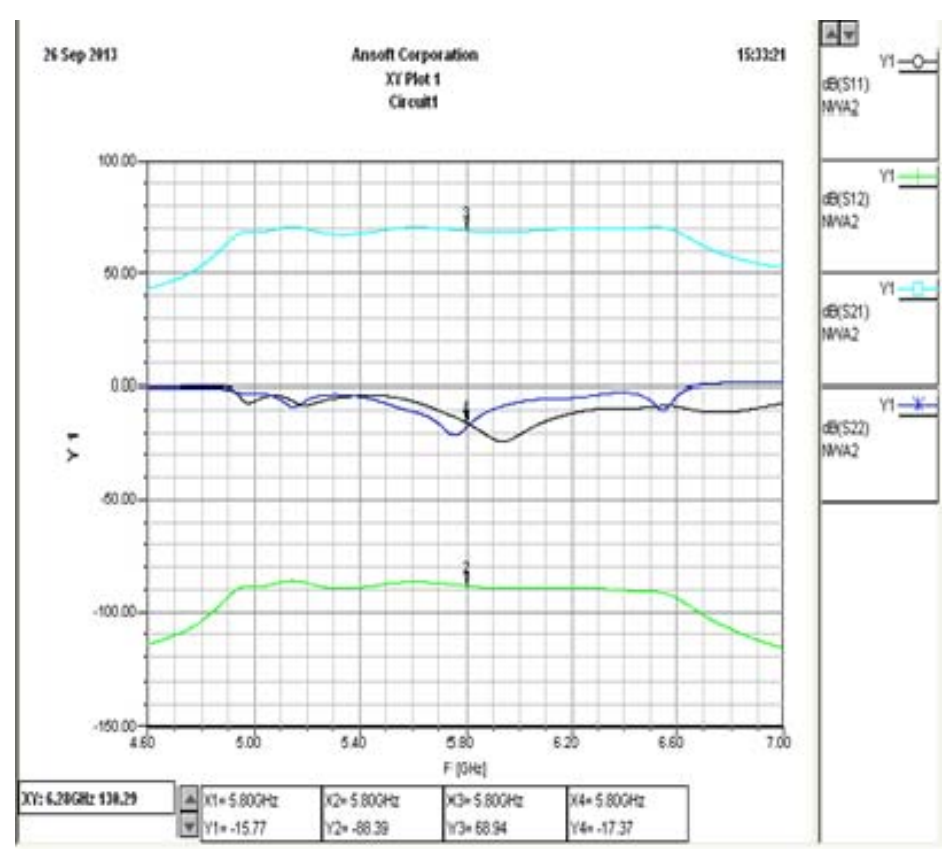

Figure 6. S-parameter for LNA Cascaded with Double Stages Cascoded LNA using the lumped - component 


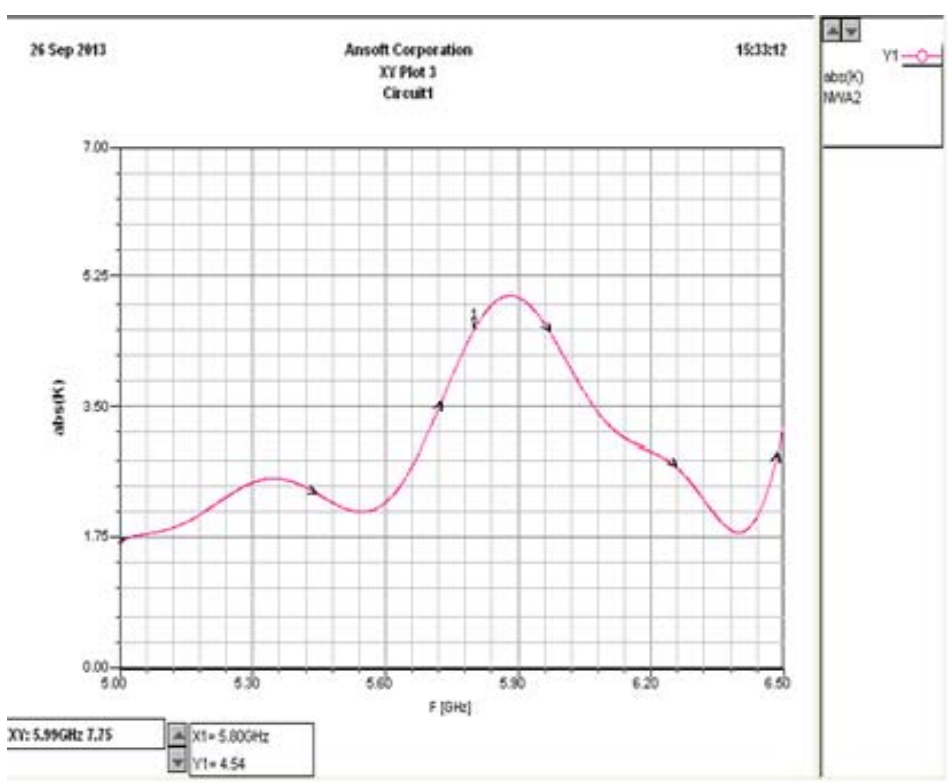

Figure 7. Stability for LNA Cascaded with Double Stages Cascoded LNA using the lumped - component

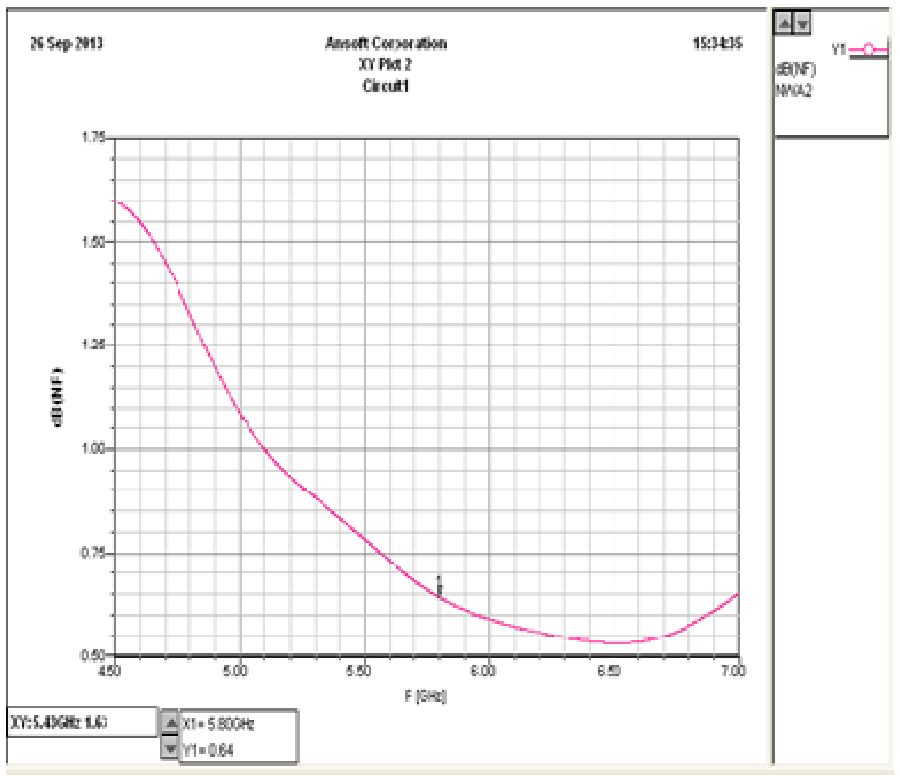

Figure 8. Noise Figure for LNA Cascaded with Double Stages Cascoded LNA using the lumped - component

Figure 9 is s-parameter output by using Murata manufactured component on the Y-Axis and frequency on the X-Axis. The low noise amplifier (LNA) using Murata manufactured component provides the gain $\mathrm{S}_{21}$ of $66.38 \mathrm{~dB}$. The output reflection $\mathrm{S}_{22}$, input reflection $\mathrm{S}_{11}$ and return loss $\mathrm{S}_{12}$ are $-13.88 \mathrm{~dB}$, $12.41 \mathrm{~dB}$ and $-89.90 \mathrm{~dB}$ respectively. In addition, the use of this topology has produced a $3-\mathrm{dB}$ bandwidth of $1.70 \mathrm{GHz}$. The gain is found to be nearly same as lumped-component during the design procedure. Another parameter that dictates the performance of the low noise amplifier is the noise figure. The noise figure of 0.60 $\mathrm{dB}$ as shown in Figure 10 is obtained at $5.8 \mathrm{GHz}$ that also satisfies the design requirements of below than $3 \mathrm{~dB}$. The Voltage Standing Wave Ratio (VSWR) at the input and output shown as Figure 11 and 12 . The $\mathrm{VSWR}_{\mathrm{IN}}$ and VSWR $\mathrm{OUT}$ curves are showing the input and output Voltage Standing Wave Ratio respectively. Both the standing wave ratios are found to be same as were calculated during the design procedure. This factor is important as it specifies phenomenon of standing waves due to reflections on the transmission line. Initially the design was given $\mathrm{VSWR}_{\mathrm{IN}}$ and $\mathrm{VSWR}_{\mathrm{OUT}}$ more than two at the input and output ports, but by 
using the ADS optimization tools VSWR's are reduced to less than two to minimize the reflections at the input and output ports.

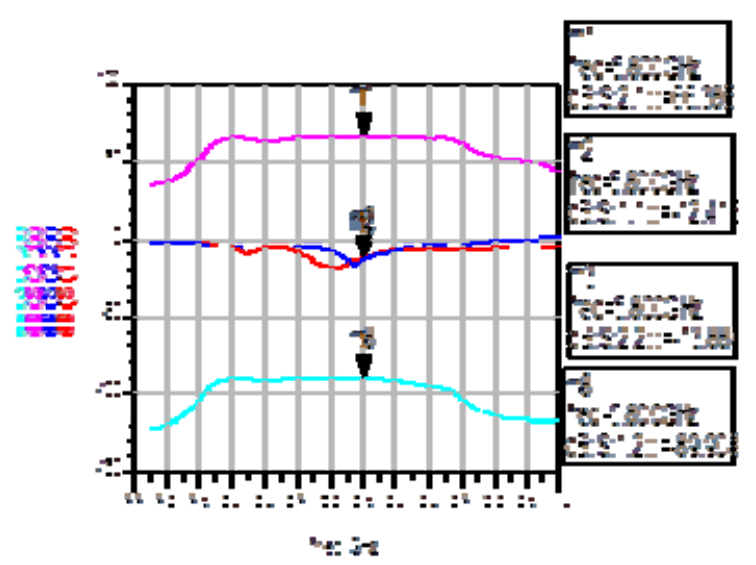

Figure 9. S-parameter for LNA Cascaded with Double Stages Cascoded LNA using Murata manufactured component

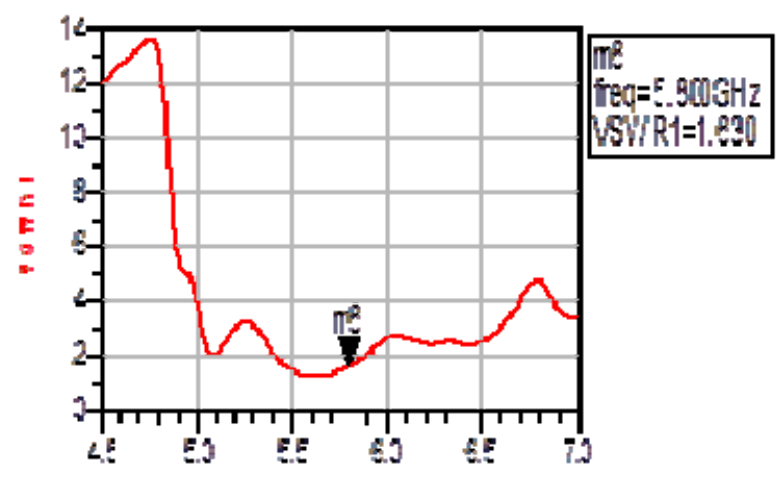

Pra $\mathrm{CH}_{2}$

Figure 11. Input VSWR for LNA Cascaded with Double Stages Cascoded LNA using Murata manufactured component
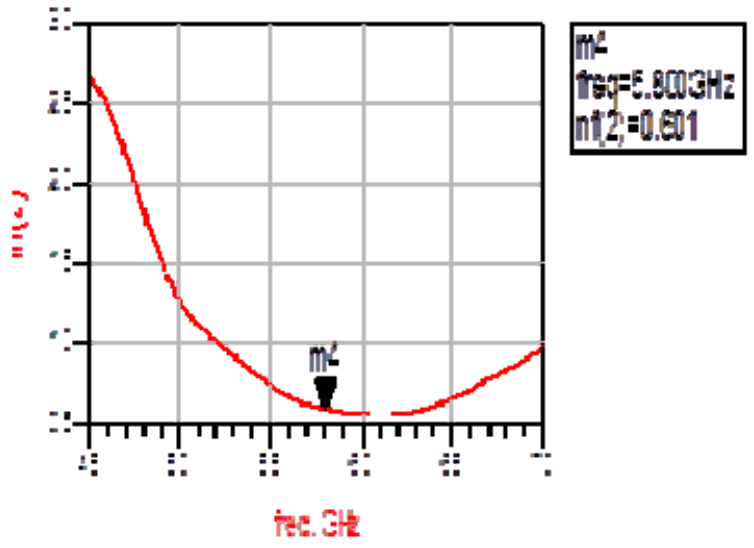

Figure 10. Noise Figure for LNA Cascaded with Double Stages Cascoded LNA using Murata manufactured component

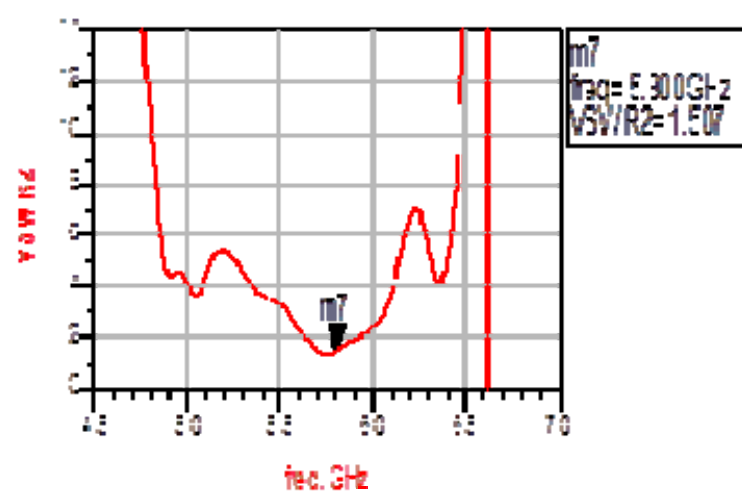

Figure 12. Output VSWR for LNA Cascaded with Double Stages Cascoded LNA using Murata manufactured component

Table 5 shows the s-parameters output for comparison of between lumped-component and Murata manufactured component by using topology single LNA cascaded with double cascoded LNA by using the inductive drain feedback. From this comparison, we find this topology has resulted in improved performance in gain, noise figure, and bandwidth. In a variable gain performance improvements can be tuned to reach to gain as a lumped - component at $68.94 \mathrm{~dB}$. Meanwhile, there was a significant reduction on noise figure of $0.64 \mathrm{~dB}$ to $0.60 \mathrm{~dB}$. Table 6 shows the comparison of recently reported LNA.

Table 5. The s-parameters output for comparison of between lumped-component and Murata manufactured

\begin{tabular}{llll}
\hline Parameter & Targeted & Lumped-Component & Murata Manufactured Component \\
\hline Input Reflection $\mathrm{S}_{11} \mathrm{~dB}$ & $<-10$ & -15.77 & -12.41 \\
Output Reflection $\mathrm{S}_{22} \mathrm{~dB}$ & $<-10$ & -17.37 & -13.88 \\
Forward transfer $\mathrm{S}_{21}$ dB & $>+65$ & $\mathbf{6 8 . 9 4}$ & $\mathbf{6 6 . 3 8}$ \\
Return Loss $\mathrm{S}_{12} \mathrm{~dB}$ & $<-10$ & -88.39 & -89.90 \\
NF dB & $<3$ & $\mathbf{0 . 6 4}$ & $\mathbf{0 . 6 0}$ \\
BW GHz & 1 & $\mathbf{1 . 7 2}$ & $\mathbf{1 . 7 0}$ \\
Stability $(\mathrm{K})$ & $\mathrm{K}>1$ & 4.54 & 6.81 \\
\hline
\end{tabular}

Design and Analysis High Gain PHEMT LNA for Wireless Application at $5.8 \mathrm{GHz}$ (Kamil Pongot) 
Table 6. Comparison of recently LNAs

\begin{tabular}{llll}
\hline $\begin{array}{l}\text { S- parameter } \\
\text { Topology }\end{array}$ & $\begin{array}{l}\text { This work } \\
\text { Single LNA Cascaded with } \\
\text { Double Stages Cascoded LNA }\end{array}$ & $\begin{array}{l}\text { (Sobhy et al., 2011) } \\
\text { CGLNA with multiplele } \\
\text { feedback }\end{array}$ & $\begin{array}{l}\text { (Karpagam and Sampath, 2013) } \\
\text { Differential LNA }\end{array}$ \\
\hline Input Reflection $\mathrm{S}_{11} \mathrm{~dB}$ & -12.41 & $<-10$ & -15.075 \\
Output Reflection $\mathrm{S}_{22} \mathrm{~dB}$ & -13.88 & $<-10$ & - \\
Forward transfer $\mathbf{S}_{21} \mathbf{d B}$ & $\mathbf{6 6 . 3 8}$ & $\mathbf{2 3}$ & $\mathbf{2 5 . 0 7}$ \\
Return Loss $\mathrm{S}_{12} \mathrm{~dB}$ & -89.90 & - & - \\
$\mathbf{N F} \mathbf{d B}$ & $\mathbf{0 . 6 0}$ & $\mathbf{2}$ & $\mathbf{1 . 0 7}$ \\
$\mathrm{BW} \mathrm{GHz}$ & $\mathbf{1 . 7 0}$ & 1.70 & - \\
Stability $(\mathrm{K})$ & 6.81 & $>1$ & 1.12 \\
\hline
\end{tabular}

\section{CONCLUSION}

The main aim was to design and analyze new topology using an inductive drain feedback implemented in PHEMT technology at $5.8 \mathrm{GHz}$. The important parameters related to microwave amplifiers are described, including gain and noise figure circles. Trade-off between noise figure and gain is also considered in point for a low noise amplifier. Obtained from the proposed topology allows the designer to control LNA variable performance, such as noise figure, bandwidth, gain and stability in the LNA circuit Recorded result for amplifier obtained the noise figure $(\mathrm{NF})$ of $0.60 \mathrm{~dB}$ and the gain $\left(\mathrm{S}_{21}\right)$ of $66.38 \mathrm{~dB}$. While the stability $(\mathrm{K})$ is 6.81 and $3-\mathrm{dB}$ bandwidth is $1.70 \mathrm{GHz}$. LNA performance can be further enhanced by strengthening input and output impedance matching of the output reflection loss $\left(\mathrm{S}_{22}\right)$, input reflection loss $\left(\mathrm{S}_{11}\right)$ and return loss $\left(\mathrm{S}_{12}\right)$ of the respective value are $-13.88 \mathrm{~dB},-12.41 \mathrm{~dB}$ and $-89.90 \mathrm{~dB}$. In conclusion, use of this topology has improved performance of the LNA amplifiers in RF receiver mainly on noise figure, gain, bandwidth, and stability.

\section{ACKNOWLEDGMENT}

The work described in this paper was fully supported by Centre For Research And Innovation Management (CRIM), Universiti Teknikal Malaysia Melaka (UTeM). Melaka, Malaysia, under research grant PJP/2013/FKEKK (11C)/S01182.

\section{REFERENCES}

[1] S. Lowe, 2007. "LTE vs WiMAX" in Hot Topics Forum: LTE vs WiMAX and Next Generation Internet. Institution of Engineering and Technology. 2007: 1-38.

[2] Pongot K, Ahmad A, Othman A.R, Zakaria Z, Suaidi M.K, Hamidon A.H, Hamidon J.S. Design High Gain PHEMT LNA for Wireless Application at $5.8 \mathrm{GHz}$. Proceeding of the 1st International Conference on Electrical Engineering, Computer Science and Informatics. 2014: 456-461

[3] Abdulrahman Yarali. WiMAX: The Innovative Broadband Wireless Access Technology. Journal of Communications. 2008; 3(2): 53-63.

[4] Othman A. R, Hamidon A. H, Abdul Wasli. C, Mustaffa M. F, Ting J. T.H, Ibrahim A.B. Low Noise, High Gain RF Front End Receiver at $5.8 \mathrm{GHz}$ for WiMAX Application. Journal of Telecommunication and Computer Engineering. 2010; 2 (2), 43-54.

[5] Somesh Kumar, Ravi Kumar. A $1.8 \mathrm{~V}$ and $2 \mathrm{GHz}$ Inductively Degenerated CMOS Low Noise Amplifier. International Journal of Electronics Communication and Computer Technology. 2012; 2(4): 150-154.

[6] David M. Pozar. Microwave and RF Wireless System. Third Avenue. N.Y.John Wiley \& Sons. 2001.

[7] Gonzales G., Microwave Transistor Amplifier. New Jersey: Prentice Hall. 1997.

[8] Abu Bakar Ibrahim, Abdul Rani Othman, Mohd Nor Husain, and Mohammad Syahrir Johal. Low Noise, High Gain LNA at $5.8 \mathrm{GHz}$ with Cascode and Cascaded Techniques Using T-Matching Network for Wireless Applications. International Journal of Information and Electronics Engineering. 2011; 1(2): 146-149.

[9] Michael Angelo G. Lorenzo, Maria Theresa G. de Leon. Comparison of LNA Topology for Wimax Application in a Standard 90-nm CMOS Process. 12th International Conference on Computer Modelling and Simulation. 2010: 642647.

[10] Sobhy, E.A.; Helmy, A.A.; Hoyos, Sebastian; Entesari, K.; Sanchez-Sinencio, E. A 2.8-mW Sub-2-dB Noise-Figure Inductorless Wideband CMOS LNA Employing Multiple Feedback. IEEE Transactions on Microwave Theory and Techniques. 2011; 59(12): 3154-3161.

[11] S. Karpagam, P. Sampath. A $1.8 \mathrm{GHz}$ Differential Low Noise Amplifier for Wireless Receivers. International Journal of Engineering Trends and Technology. 2013; 4(4): 558-564. 